\title{
Identification and characterization of two repetitive non- variable antigens from African trypanosomes which are recognized early during infection
}

\author{
N. MÜLLER ${ }^{1}$, A. HEMPHILL $L^{1}$, M. IMBODEN ${ }^{1}$, G. DUVALLET ${ }^{2}, R$. H. DWINGER \\ and T. SEEBEC K ${ }^{1}$ \\ ${ }^{1}$ Institute of General Microbiology, University of Berne, Baltzerstrasse 4, 3012 Berne, Switzerland \\ ${ }^{2}$ Centre de Recherches sur les Trypanosomes Animales (CRTA), BP 454, Bobo-Dioulasso 01, Burkina Faso \\ ${ }^{3}$ International Trypanotolerance Centre (ITC), PMB 14, Banjul, The Gambia
}

(Received 30 April 1991; revised 2 August 1991; accepted 9 August 1991)

SUMMARY

The present paper describes two repetitive proteins representing common antigens of African trypanosomes which are non-variant and which are recognized early in infection by the host immune system. These antigens were identified by their ability to immunoreact with bovine serum taken during the early phase of a cyclic trypanosomal infection. Screening of a cDNA library from $T$. b. gambiense with such early infection serum identified a protein which contains a repetitive motif consisting of 68 amino acid repeat units (GM6). Immunofluorescence and immunogold electron microscopy revealed that GM6 is located on fibres which connect the microtubules of the membrane skeleton with the flagellum. A second repetitive antigen detected by this serum is MARP1 (microtubule-associated repetitive protein 1), a protein previously characterized in this laboratory as a high-molecular weight component of the membrane skeleton, which consists of more than 50 tandemly repeated, near-identical 38 amino acid repeat units. Beta-galactosidase fusion products of both proteins demonstrated a strong immunoreactivity with sera from $T . b$. brucei and $T$. congolense-infected cattle. The result from this preliminary immunological evaluation indicates a high immunodiagnostic sensititivy (90\%) of the two recombinant antigens which make them interesting candidates for immunodiagnosis of trypanosomiasis in cattle.

Key words: African trypanosomes, DNA cloning, recombinant antigen, repetitive protein, immunodiagnosis, cytoskeleton.

\section{INTRODUCTION}

Mammalian hosts which have been infected with African trypanosomes exhibit a strong humoral immune response against the parasite during the early phase of the infection. The major part of this response is directed against the variant surface glycoproteins (VSGs; Cross, 1990). However, a strong antibody response against VSGs is not sufficient to cure the host nor to protect it from a subsequent infection, and several analyses have demonstrated that the ability to mount an antibody response against VSG and the ability to survive a trypanosome infection are genetically unlinked (DeGee, Levine \& Mansfield, 1988; Seed \& Sechelski, 1987). However, observations have indicated that, besides the anti-VSG response, infected mammalian hosts also produce antibodies against minor, and non-variable, antigens (Shapiro \& Murray, 1982; Burgess \& Jerrells, 1985; Frommel \& Balber, 1987). Many of these non-variable antigens may represent household cell-surface proteins such as receptors (Hide et al. 1989) or transporters (Parsons \& Nielsen, 1990; Webster \& Shapiro, 1990) which are expected to remain conserved not only between trypanosome serodemes, but also between different trypanosomatid species or even genera.

The purpose of the present study was the identification of protein antigens from African trypanosomes which are (i) recognized early during infection by the bovine immune system and which are (ii) non-variable. Two of such proteins were characterized in more detail and turned out to be highly repetitive. Both antigens are recognized early during infection by antibodies of the IgM class, and they are conserved both between different life-cycle stages and between different trypanosome species. A preliminary survey of infected bovine sera indicates that antibodies against these two proteins are present in almost all infected individuals. Thus, they may present promising candidates for the serodiagnostic detection of trypanosomal infections.

\section{MATERIALS AND METHODS}

\section{Trypanosomes}

T. b. brucei clone EATRO 427 was grown as procyclics in SDM-79 medium (Brun \& Schönenberger, 1979) supplemented with haemin and $5 \%$ foetal calf serum. 
T. b. brucei stock Farakoba/80/CRTA/1 and $T$. congolense stock Karankasso/83/CRTA/57 were isolated and cloned at the Centre de Recherches sur les Trypanosomes Animales (CRTA) in BoboDioulasso, Burkina Faso. T. b. brucei stock ITC 091 was isolated from an equine near Georgetown, The Gambia in February 1990 and was cloned at the International Trypanotolerance Centre (ITC) in Banjul, The Gambia. Stabilates from the CRTA were prepared by passaging through rabbits and stabilates from the ITC by passaging through mice. Blood from these infected animals was used for cyclic or experimental infection of cattle (see below).

\section{Sera}

Sera 526, 406 and 615 originated from cattle which were cyclically infected with $T$. b. brucei stock Farakoba/80/CRTA/1 as described by Duvallet (1984). As vectors for inoculation, infected Glossina palpalis gambiensis females (CRTA colony) were used. Serum 526 and serum 406 originated from taurines and were taken 7 and 56 days post-infection, respectively. Serum 615 originated from a zebu and was taken 19 days post-infection. Sera from experimentally infected cattle were obtained as follows: $T$. $b$. brucei infections were performed by using stock ITC091 for intradermal inoculation and $T$. congolense infections by using Karankasso/83/CRTA/ 57 clone 1 for subcutaneous inoculation. The inoculum was $>5 \times 10^{3}$ trypanosomes for both types of infection. Sera from T. b. brucei infections were taken 14 days and those from $T$. congolese infections about 2 months post-infection. All cattle were maintained in areas which were free of tse-tse flies.

Hyperimmune sera were raised in rats with proteins purified by gel electrophoresis. Animals were inoculated intraperitoneally with macerated polyacrylamide gel slices which were homogenized either in complete (1st inoculation) or incomplete (2nd and 3rd inoculation) Freund's adjuvants. Blood was finally collected by cardiac puncture.

\section{Lambda gt 11 phage cDNA expression library of}

T. b. gambiense

The cDNA expression library from bloodstream form T. b. gambiense (stock TREU 1285) was constructed in the cloning vector $\lambda \mathrm{gt} 11$ as described (Barnes et al. 1989) and was kindly provided by Murray Selkirk (Department of Biochemistry, Imperial College of Science, Technology, and Medicine, London).

\section{DNA preparation and cloning methods}

Phage and plasmid DNA preparation, digestion of DNA with restriction endonucleases, ligation of DNA and gel electrophoretic size determination of
DNA fragments were according to Sambrook, Fritsch \& Maniatis (1989).

\section{DNA sequencing and comparative analysis of the sequence with a data bank}

The 670 bp $E c o$ R1/EcoR1 cDNA fragment from recombinant clone $\lambda \mathrm{GM} 6$ (see Results section) was subcloned into the EcoR1 site of Bluescript plasmid KS-Plus (Stragene). Further subclones were constructed by using two internal Hind 3 sites of the EcoR1 insert for creating a 130 bp EcoR1/Hind 3 and a 200 bp Hind3/Hind3 fragment which were cloned into Bluescript plasmid KS-Plus, and a $340 \mathrm{bp}$ $H$ ind $3 / E c o$ R1 fragment of the GM6 sequence which was cloned into M13 phage mp19 (Norrander, Kempe \& Messing, 1983). The approximate size of the fragments was determined by $0.8 \%$ agarose and $6 \%$ acrylamide gel electrophoresis. The 3 subclones served as templates for single and double strand sequencing performed with the sequenase kit (United States Biochemical Corp., Cleveland, $\mathrm{OH}$ ) following the dideoxy procedure of Sanger, Nicklen $\&$ Coulson (1977) according to the instructions of the manufacturer. The sequence was analysed and compared to the GenBank/EMBL sequence data bank using the GCG software.

\section{Immunoscreening of a $c D N A$ expression library and construction of recombinant $\lambda$ lysogen}

The $\lambda g t 11$ cDNA expression library of $T . \quad b$. gambiense was screened for antigen-producing phages according to the method of Hyunh, Young \& Davis (1985). Production of phage plaques and transfer of the plaques onto nitrocellulose filters (previously soaked in $10 \mathrm{~mm}$ IPTG) was done as already described (Vogel et al. 1988). For detection of antigen-producing clones $132 \mathrm{~mm}$ replica filters (Schleicher \& Schuell) containing about $5 \times 10^{4}$ plaques were incubated overnight at $4{ }^{\circ} \mathrm{C}$ with serum 526 (see above). The serum was diluted $1: 10$ in TBS $(10 \mathrm{~mm}$ Tris- $\mathrm{HCl}, \mathrm{pH} 7 \cdot 4,150 \mathrm{~mm} \mathrm{NaCl}$ ) containing $5 \%$ horse serum. Antibodies to wild-type $\beta$ galactosidase and other compounds of $E$. coli as well as antibodies to phage were previously removed by pre-adsorption of the serum to a lysate of $\lambda \mathrm{gt} 11$ lysogens from strain Y1089 (Huynh et al. 1985) according to Hohn (1980). After washing the filters twice with TBS containing $0.05 \%$ Tween 20 and once with TBS without Tween $20(10 \mathrm{~min} /$ wash $)$, the filters were incubated for $4 \mathrm{~h}$ at room temperature with peroxidase-conjugated sheep antibodies to cow IgM ( $\mu$ chain) (The Binding Site LTD, Birmingham, UK), diluted $1: 500$ in TBS containing 5\% horse serum. The filters were washed again 3 times as described above. The peroxidase-dependent colour reaction for visualization of the antibody-antigen 
immunocomplexes, purification of immunopositive plaques, production of high titre lysates from recombinant phages and construction of recombinant $\lambda$ gt11 lysogens in strain Y1089 were performed as described elsewhere (Vogel et al. 1988).

\section{Western blot analysis}

For Western blot analysis of MARP1 and GM6/ $\beta$ galactosidase fusion proteins cell extracts from lysogens of $\lambda$ T.b. MARP 1.1 (Schneider et al. 1988) and $\lambda$ GM6 were prepared according to Hyunh et al. (1985). Bacterial cell lysates from $10^{9}$ cells were solubilized in $200 \mu \mathrm{l}$ of sample buffer (Laemmli, 1970). Protein extracts from cultured trypanosomes (see above) were obtained by washing $10^{8}$ cells once with PBS, (137 $\mathrm{mm} \mathrm{NaCl}, 2.6 \mathrm{~mm} \mathrm{KCl}, 8 \mathrm{~mm}$ $\mathrm{Na}_{2} \mathrm{HPO}_{4}, 1.5 \mathrm{mM} \mathrm{KH} \mathrm{PO}_{4}, \mathrm{pH} 7.2$ ) followed by solubilizing the cells in $1 \mathrm{ml}$ of sample buffer containing $6 \mathrm{M}$ urea. After boiling the bacterial and trypanosomal protein extracts for $5 \mathrm{~min}$, proteins were separated by SDS-PAGE (10\% gel) and blotted onto nitrocellulose filters (Schleicher \& Schuell) as described by Towbin, Staehelin \& Gordon (1979). Then the filters were blocked for $1 \mathrm{~h}$ at room temperature with TBS, containing $5 \%$ horse serum.

For Western blot analysis of the fusion proteins crude protein extracts from $5 \times 10^{7} \mathrm{E}$. coli lysogens were fractionated on $8 \%$ SDS-PAGE gels and then blotted onto nitrocellulose. Immunostaining was done with serum 526 (see above) by using the conditions for detecting the IgM specific antibody antigen complexes as described for the screening of the cDNA expression library (see above).

In blot experiments for the determination of the diagnostic sensitivity of the recombinant antigens, nitrocellulose sheets containing the blotted proteins were cut into strips. Strips were exposed overnight at $4{ }^{\circ} \mathrm{C}$ to pre-adsorbed, infected cattle sera (see above) which had previously been diluted $1: 50$ with TBS containing $5 \%$ horse serum. As second antibody, a rabbit anti-cow Ig (Dakopatts, Denmark) was used.

Blotted trypanosomal proteins were incubated with rat hyperimmune sera raised against MARP1 or GM6/ $\beta$-galactosidase fusion protein, respectively (see above). In this experiment rabbit anti-rat Ig (Dakopatts, Denmark) served as second antibody.

\section{Affinity purification of antibodies on fusion protein}

MARP1 and GM6/ $\beta$-galactosidase fusion proteins (approximately $10 \mu \mathrm{g}$ ) were produced and blotted onto nitrocellulose filters as described for the Western blot (see above). After staining with $0.04 \%$ Ponceau $\mathrm{S}$ in $10 \%$ acetic acid, the band corresponding to the fusion proteins was excised. The strip was blocked for $1 \mathrm{~h}$ at room temperature with TBS containing $5 \%$ horse serum and incubated overnight at $4{ }^{\circ} \mathrm{C}$ with rat hyperimmune serum raised against fusion protein (see above) that had previously been diluted $1: 5$ in TBS containing $5 \%$ horse serum. After washing 3 times for $10 \mathrm{~min}$ with TBS containing $0.05 \%$ Tween 20 , the adsorbed antibodies were eluted according to the method described by Goldstein, Laymon \& McIntosh (1986).

\section{Immunofluorescence}

In vitro cultivated trypanosomes (see above) were washed twice with PBS and drops of the final cell suspension (approximately $10^{7}$ cells $/ \mathrm{ml}$ ) were applied to cover-slips previously coated with $100 \mu \mathrm{g} / \mathrm{ml}$ polylysin $\left(M_{\mathrm{r}} 389 \mathrm{kDa}\right)$. Cells were allowed to settle down for $1 \mathrm{~h}$ in a moist chamber at room temperature. Cover-slips were rinsed twice in MME (100 mM 3-morpholinopropane sulphonic acid (MOPS), $5 \mathrm{~mm} \mathrm{MgCl}_{2}, 1 \mathrm{~mm}$ ethylene glycol$O, O^{\prime \prime}$-bis(2-aminoethyl)- $N, N, N^{\prime}, N^{\prime}$-tetraacetic acid (EGTA, pH 6.9) and treated with $3 \%$ paraformaldehyde in MME for $15 \mathrm{~min}$. Then the fixed trypanosomes were permeabilized in methanol at $-20^{\circ} \mathrm{C}$ for $10 \mathrm{~min}$ and subsequently rehydrated in PBS for $30 \mathrm{~min}$. For the preparation of cytoskeletons, cells were extracted for $5 \mathrm{~min}$ at room temperature in MME containing $0.2 \%$ Triton $\mathrm{X}$ 100 prior to fixation. Blocking of the cover-slips was performed by incubation for $1 \mathrm{~h}$ in blocking buffer (PBS containing $100 \mathrm{~mm}$ L-lysine and $1 \% \mathrm{BSA}$ ). For the immuno-staining cover-slips were incubated for $45 \mathrm{~min}$ in a moist chamber at room temperature with affinity-purified antibodies from rat antiMARP1/ $\beta$-galactosidase fusion protein or antiGM6/ $\beta$-galactosidase fusion protein hyperimmune sera (see above). After washing the cover-slips 6 times in PBS FITC-conjugated rabbit anti-rat Ig (Dakopatts, Denmark) was applied as described for the affinity-purified antibody. The affinity-purifed antibodies were diluted $1: 10$ and the second antibodies 1:100 in blocking buffer to prevent nonspecific antibody binding. After removing excess second antibody by washing 6 times in PBS, coverslips were mounted on a slide using a previously described (Lawson, 1983) mixture of gelvatol/ glycerol in PBS as embedding medium.

\section{Immunogold electron microscopy}

Washed trypanosomes were allowed to settle onto a Formvar carbon-coated grid for $1 \mathrm{~h}$ prior to extraction in MME containing $0.2 \%$ Triton X-100 as described above. This cytoskeleton preparation was found to be ideal for the preservation of cell body/flagellum cross-links (Hemphill, Lawson \& Seebeck, 1991). After rinsing the cover-slips in MME, the cytoskeletons were fixed in $3 \%$ formaldehyde in MME, incubated in blocking buffer 


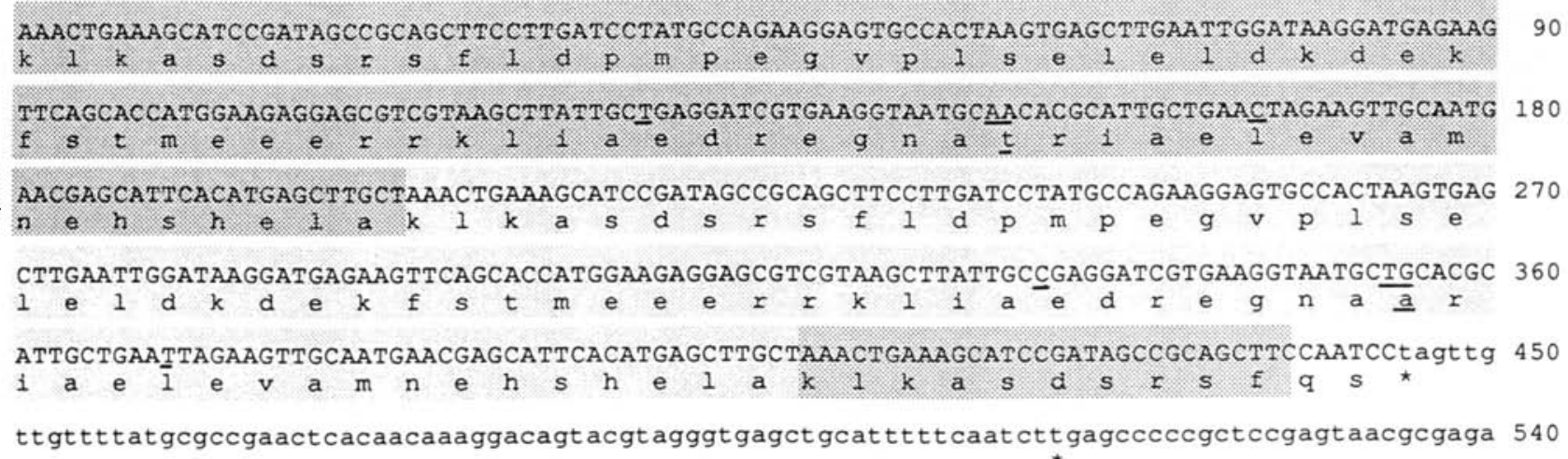

agtcgagaggcccaagccccagcaaggccggagatgtggattatggtgaaaagaagctcaccgtgggaggtggagatatagcattcgacg 630

GM6 KLKASDSRSFLDPMPEGVPLSELELDKDEKESTMEEERRKLIAEDREGNATRIAELEVAMNEHSHELA T.cruzi $\quad:|\quad \ldots|:|||\ldots|||||||||.|.| \ldots|:||:|||:: \ldots||||. .|1| 1:||:.::|| \mid$ antigen 1 REKKLADRAFLDQKPEGVPLRELPLDDDSDFVAMEQERRQQLEKDPRRNAKE IAALEE SMNARAOELA

Fig. 1. Sequence analysis of the insert in $\lambda$ GM6. (A) $\lambda$ GM6 cDNA sequence and the deduced amino acid sequence. The different repeat units are represented by different grey tones. The positions of nucleotide or amino acid replacements between the different repeats are underlined. The non-coding DNA sequence is written in small characters. In frame stop codons are indicated with asterisks. The sequence has been deposited in the GenBank/EMBL data library under the accession number X58788 TB GAMB.GM6. (B) Alignment of the first GM6 repeat to a repeat unit of Trypanosoma cruzi antigen 1. Amino acids that are identical are indicated with a bar, those that are positively related with a colon, the zero-value related with a period and the negatively related with a blank.

and exposed to the antibodies according to the immunofluorescence method with the modification that the second antibody was an affinity-purified goat anti-rat IgG coupled to $10 \mathrm{~nm}$ colloidal gold (Janssen, Beerse, Belgium) diluted $1: 5$ in $20 \mathrm{~mm}$ Tris- $\mathrm{HCl}$, pH 8.2, containing $1 \%$ BSA. After intensive washing of the grids in PBS $(6$ times, $5 \mathrm{~min} /$ wash), fixation was done in $2 \%$ glutaraldehyde for $20 \mathrm{~min}$. Grids were washed 6 times in $\mathrm{H}_{2} \mathrm{O}$ and negative staining was carried out in 3 changes of $1 \%$ uranyl acetate, $20 \mathrm{~s}$ each. Finally, grids were air-dried and electron micrographs were taken with a Philips EM 300 microscope operating at $60 \mathrm{kV}$.

\section{RESULTS}

Heterologous screening of a $\mathrm{T}$. b gambiense library with a 7-day post-infection serum of a bovine infected with T. b. brucei

In an attempt to identify trypanosomal antigens which are (i) conserved between different trypanosomal species and which are (ii) recognized by the host immune system early during infection, the following screening strategy was applied. A cDNA library from bloodstream $T$. b. gambiense (Barnes et al. 1989) in $\lambda \mathrm{gt} 11$ (10 $0^{5}$ phages) was immunoscreened with serum taken from a taurine 7 days after cyclic infection with $T$. b. brucei (serum 526; Duvallet, 1984). In order to make the screen still more specific for antigens recognized early, peroxidase-labelled anti-bovine-IgM was used as the second antibody. The phages recovered from this screen represent a number of different genes, and one of them, GM6, was further analysed in this study.

GM6 is a repetitive antigen with sequence similarity to $\mathrm{T}$. cruzi antigen 1

The GM6-insert from a recombinant $\lambda$ gt11 phage was subcloned into Bluescript plasmid KS-Plus and M13mp19 and was sequenced. The $670 \mathrm{bp}$ fragment analysed contained two complete and one incomplete copies of highly conserved, tandemly arranged $204 \mathrm{bp}$ (68 amino acid) repeat units (Fig. 1A). Nucleotide replacements were seen in only 4 posi- 

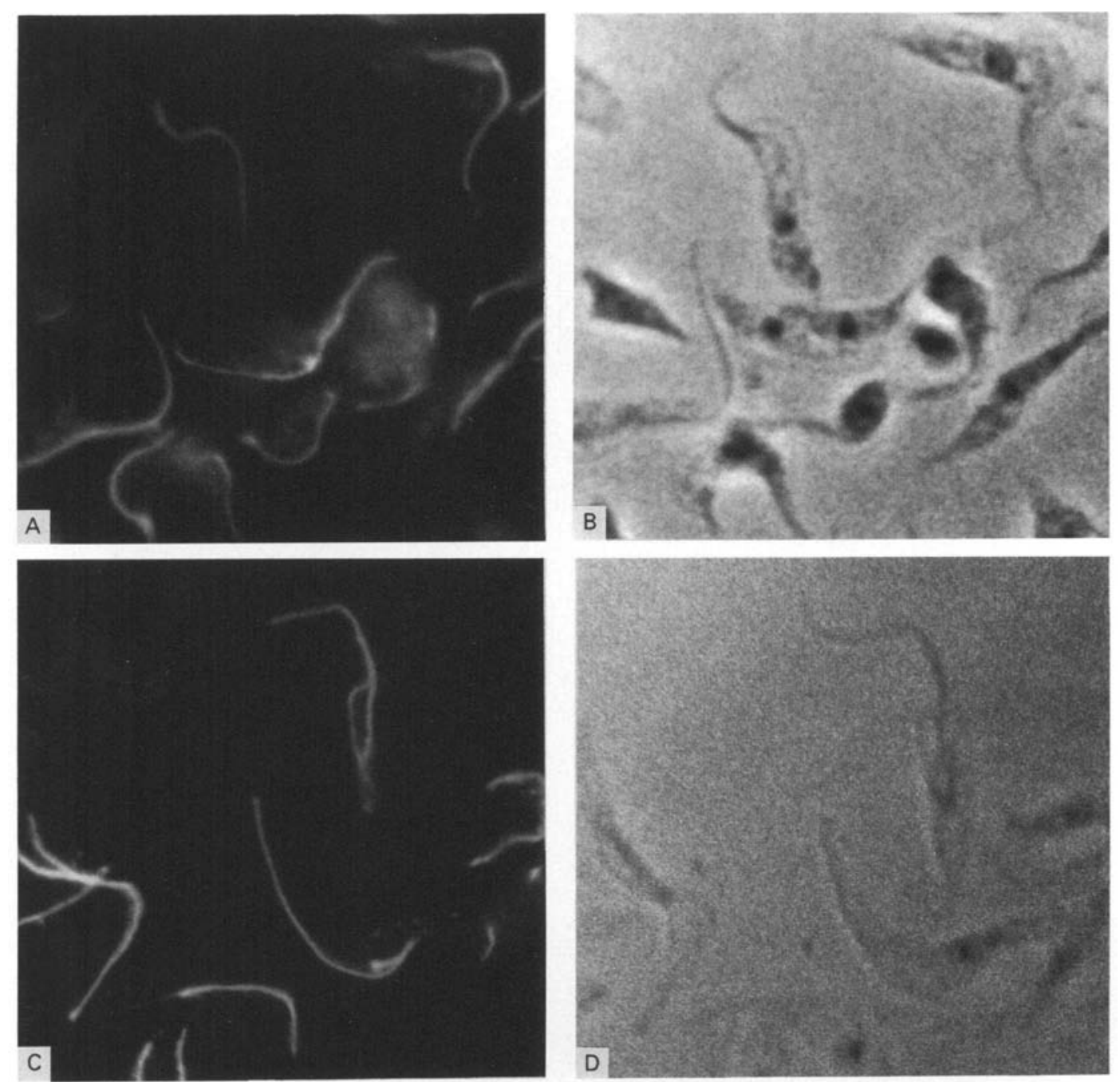

Fig. 2. Cellular localization of GM6 by immunofluorescence microscopy with formaldehyde/methanol fixed cells (A and $\mathrm{B}$ ) and cytoskeletal preparations (C and D) of procyclic Trypanosoma b. brucei. Immunofluorescence is shown in panels $\mathrm{A}$ and $\mathrm{C}$, the corresponding phase-contrast micrographs in panels $\mathrm{B}$ and $\mathrm{D}$.

tions, resulting in a single amino acid substitution (threonine to alanine at position 51 of repeats 1 and 2). At the $3^{\prime}$-end of the last repeat, two non-repeat codons were found, followed by an in-frame stop codon. This observation suggests that the cloned insert represents the 3 -terminus with a non-repetitive C-terminus of only 2 amino acids length. Restriction analysis of genomic DNA confirmed the repetitive structure of the GM6 gene(s) and indicated that GM6 is coded for by a very large gene which consists predominantly of the repetitive 204 bp motif (unpublished observations).

Database searching with the GM6 amino acid sequence revealed considerable similarity with an antigen from $T$. cruzi which had been isolated by immunoscreening with infected patient sera (antigen 1, Ibanez et al. 1988). Antigen 1 from $T$. cruzi and GM6 from $T$. b. gambiense both consist of conserved 68 amino acid repeat units and they share $50 \%$ similarity (Fig. 1 B).

\section{Immunocytochemical localization of GM6}

GM6/ $\beta$-galactosidase fusion protein was prepared from a $\lambda$ GM6 lysogen, and polyclonal antibodies were raised in rats as described in the Materials and Methods section. Antibodies to be used for immunofluorescence and immunogold electron microscopy were affinity purified on the GM6 fusion protein.

Immunofluorescent staining of formaldehyde/ methanol-fixed whole cells (Fig. $2 \mathrm{~A}$ and $\mathrm{B}$ ) or cytoskeletons (Fig. 2C and D) with affinity-purified GM6 antibody results in bright fluorescence along the flagellum. Characteristically, the flagellum is not labelled over its entire length, but the label is exclusively associated with that part of the flagellum which is tethered to the cell body. The free section of the flagellum which protrudes beyond the anterior end of the cell body (see micrographs in Fig. 2 B and D) was not labelled, or only very weakly, by the antibody. These observations indicate that GM6 is a 

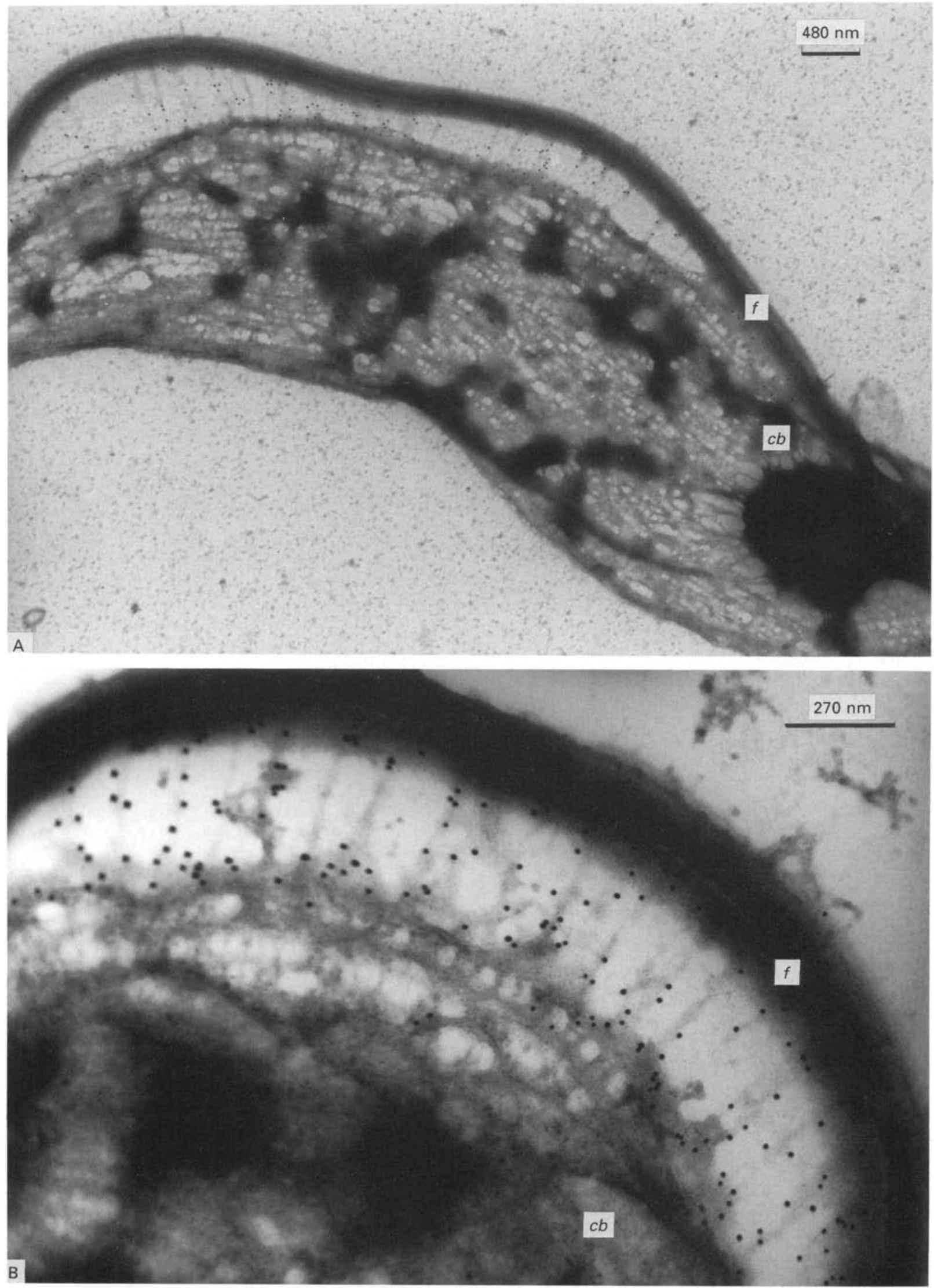

Fig. 3. Immunogold labelling of GM6 with negatively stained whole mount cytoskeleton preparation. (A) Gold particles present on fibrous structures which connect the flagellum $(f)$ to the cell body $(c b)$. (B) Higher magnification view of the flagellum/cell body interphase. 


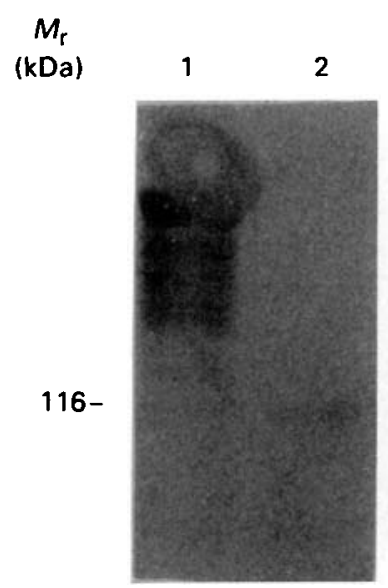

A

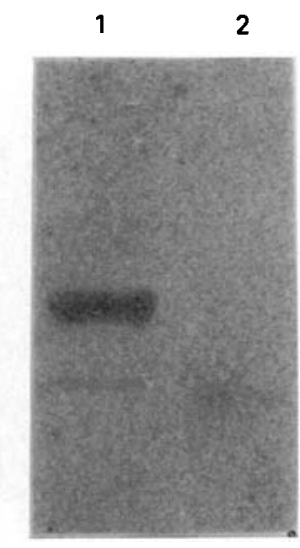

B
Fig. 4. Western blot analysis of the immunoreactivity of MARP1 and GM6 fusion proteins with Trypanosoma $b$. brucei-infected cow serum 526. Lanes $1 \mathrm{~A}$ and $1 \mathrm{~B}$ contain extracts from lysogens of $\lambda$ Tb MARP 1.1 and from $\lambda$ GM6, respectively. Lanes $2 A$ and $2 B$ contain extract from lysogens of $\lambda \mathrm{gt} 11$. On the left, the position of the $116 \mathrm{kDa}$ wild-type $\beta$-galactosidase is indicated.

structural protein of the trypanosomal cell which is located at the flagellum/cell body adhesion zone. Interestingly, a similar location has been proposed for antigen 1 of T. cruzi (Souto-Padron et al. 1989) which shares similarity with GM6 (see above).

The localization of GM6 at the flagellum/cell body interphase was further confirmed by immunoelectron microscopy. Immunogold labelling of whole cytoskeletons resulted in abundant labelling at the flagellum/cell body interphase. This labelling is seen particularly well in specimens where flagellum and cell body have become spacially separated during specimen preparation (Fig. $3 \mathrm{~A}$ ). On higher magnification, the GM6 label is seen to be associated with a network of fibres extending between the microtubules of the cell body and the flagellum (Fig. 3 B). These abundant fibrous connections are an important component of flagellum/cell body interaction, and they have recently been analysed in more detail by quick-freeze, deep-etch, rotary shadowing electron microscopy (Hemphill et al. 1991).

\section{MARP1 a microtubule-associated protein is also recognized as an early antigen during infection}

When serum 526 was used to analyse a number of recombinant trypanosomal proteins which had been produced in this laboratory earlier from different lines of experiments, one of these proteins was found to react specifically with the IgM antibody from the 526 serum. The reactive protein was MARP1, a highly repetitive, microtubule-associated protein which consists of $>50$ tandemly arranged, conserved 38 amino acid repeat units (Schneider et al. 1988). A MARP1/ $\beta$-galactosidase fusion protein strongly reacts with $\mathrm{IgM}$ antibody from serum 526
(Fig. 4) while authentic beta-galactosidase does not. This observation clearly indicates that MARP1, though being an intracellular cytoskeletal protein, is also an antigen which is recognized early during a trypanosome infection.

As a control, the same serum was also applied for staining the GM6/ $\beta$-galactosidase fusion protein and a $\beta$-galactosidase control. A comparison of the immunoblots shown in Fig. 4 demonstrates that IgM from serum 526 reacts strongly and specifically both with MARP1 and with GM6, confirming that both antigens are recognized early during infection.

GM6 and MARP1 are both high molecular weight proteins which are conserved between life-cycle stages and between different trypanosomal species

In order to establish further if these two proteins qualify indeed as being non-variant antigens, bloodstream and procyclic ('insect') forms of $T$. b. brucei were analysed for the presence or absence of these proteins. Whole cell lysates from $T . b$. brucei in the two life-cycle stages were electrophoretically fractionated and probed with the hyperimmune sera against the respective fusion proteins. As shown in Fig. $5 \mathrm{~A}$ and $\mathrm{B}$, the staining patterns obtained with either GM6 or MARP1 antiserum are very similar between the two life-cycle stages (Lanes 1 and 2). GM6 and MARP1 both are high molecular weight proteins. A closer inspection of the degradation products of MARP1 visible on these gels shows the regular ladder pattern which is formed by partial proteolysis and which is due to the highly repetitive structure of MARP1 (Schneider et al. 1988). The repetitive motif of GM6 is less conspicuous, though it can be detected under conditions of more carefully controlled proteolysis (unpublished observations). Restriction analysis of genomic DNA from $T . b$. bruce $i$ has unambiguously established the repetitive structure of the genes coding for MARP1 (Affolter et al., unpublished observations) and of GM6 (Weber et al., unpublished observations). The patterns shown indicate that neither of the two proteins is stage-specific, a notion which is compatible with the observed structural role of the two proteins within the cellular architecture.

Having established the invariance of the two antigens between life-cycle stages of $T . b$. bruce $i$ their species-specificity was analysed. Whole cell extracts from different species of procyclic-form trypanosomes $(T . \quad b$. brucei, $T$. congolense, $T$. evansi, $T$. rangeli and $T$. cruzi) were electrophoresed and probed with antisera against GM6 and MARP1 (Fig. $5 \mathrm{~A}$ and B, Lanes 2-6). Very strong signals were obtained with $T$. b. brucei, $T$. congolense and $T$. evansi with both antisera. The South-American species $T$. rangeli and $T$. cruzi show less reactivity, $T$. rangeli reacting more strongly with MARP1 serum than $T$. cruzi, with the reactivity towards GM6 serum 


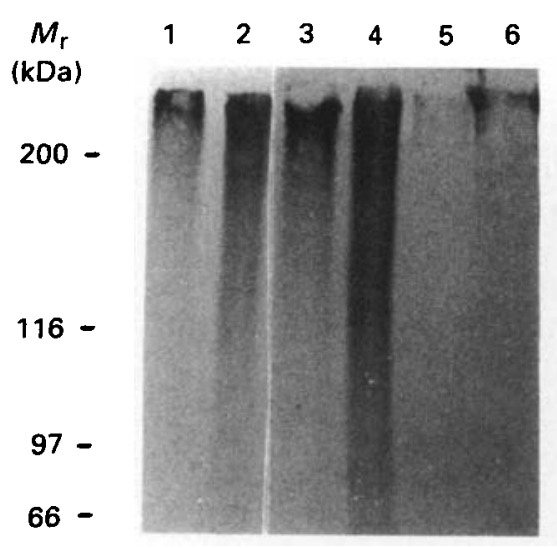

A

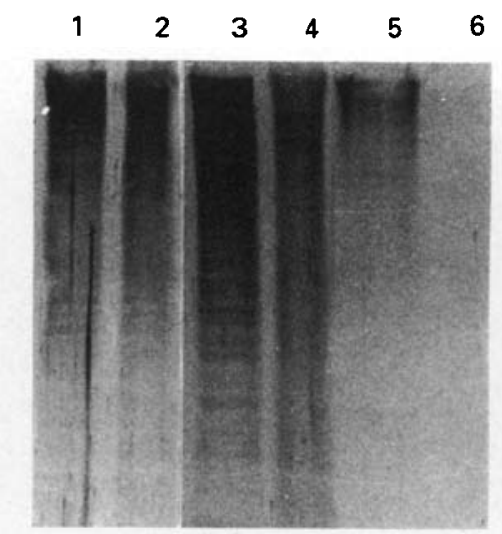

B

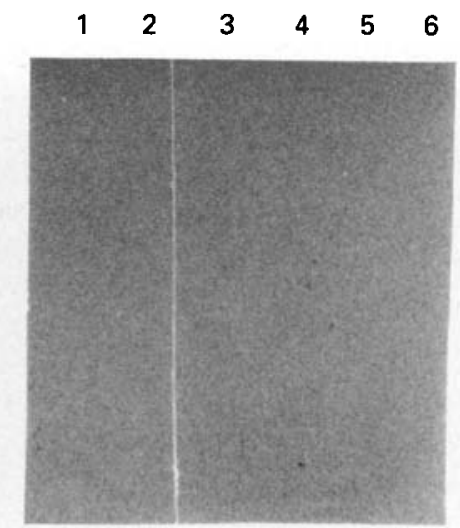

C

Fig. 5. Western blot analysis showing that MARP1 and GM6 are conserved trypanosomal antigens. Filters were incubated with hyperimmune sera raised against GM6 fusion protein (A) or MARP1 fusion protein (B), respectively. (C) Filter incubated with a negative control serum. All blots contain extracts from bloodstream form cells of Trypanosoma $b$. brucei (Lane 1) and from procyclic form cells of $T . b$. brucei (Lane 2), T. congolense (Lane 3), $T$. evansi (Lane 4), $T$. rangeli (Lane 5), $T$. cruzi (Lane 6). Molecular weight markers are given in $\mathrm{kDa}$.

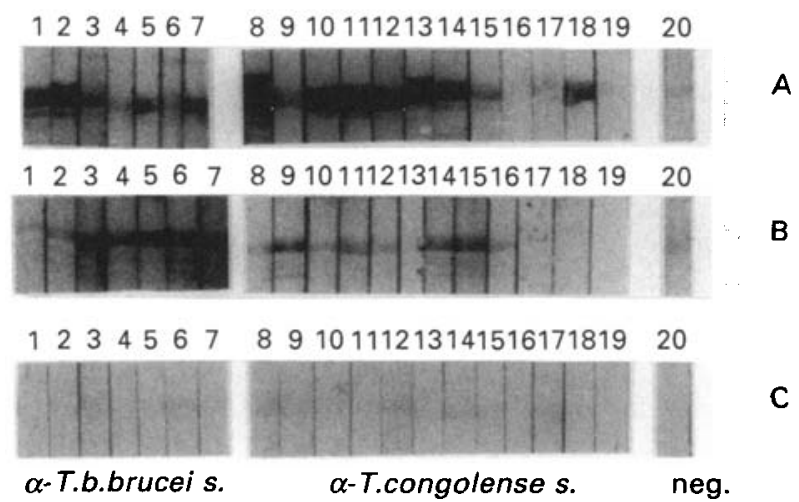

Fig. 6. Western blot analysis demonstrating the diagnostic sensitivity of the GM6 and MARP1 fusion proteins. Protein extracts from $E$. coli lysogens of $\lambda \mathrm{GM} 6$ (A) $\lambda \mathrm{Tb}$ MARP 1.1 (B) and $\lambda \mathrm{gt} 11$ (C) were blotted and cut into strips. Each strip was then incubated with serum from Trypanosoma b. brucei infections (Lanes 1-7) or from $T$. congolense infections (Lanes 8-19). Sera from cyclic infections are shown in Lane 1 (serum 406) or Lane 2 (serum 615) and those from experimental infections in Lanes $3-19$. Strip 20 was incubated with a serum from an uninfected cow.

being the reverse. These results indicate that both, GM6 and MARP1, are non-variant antigens which are well conserved between a range of trypanosomal species. Recent fluorescence microscopy data indicated that analogues of both proteins also may be present in at least some species of Leishmania (unpublished observations), further supporting the notion that they are well conserved not only between different life-cycles stages, but also between different trypanosomal species.

\section{Immunodiagnostic sensitivity of GM6 and MARP1}

The studies described above have characterized MARP1 and GM6 as repetitive antigenic proteins immunoreacting with the $T . b$. brucei-infected bovine serum 526. The strong antigenicity of the two recombinant antigens and the fact that both are recognized early during infection suggested their potential as immunodiagnostic probes.

In this context, a preliminary evaluation of the immunodiagnostic sensitivity of the GM6 (Fig. 6A) and the MARP1/ $\beta$-galactosidase fusion protein (Fig. $6 \mathrm{~B})$ was performed in a Western blot experiment by using a set of T.b. brucei and T. congolense-infected sera originating from different cattle breeds. In each panel, one uninfected control serum is included. In order to avoid false positive signals caused by anti $\beta$ galactosidase antibodies, sera were pre-adsorbed to lysates of $\beta$-galactosidase producing lysogens of $\lambda$ gt11 as described in the Materials and Methods section. This pre-treatment nearly completely removes antibodies directed against $\beta$-galactosidase (Fig. 6C). From 19 trypanosome-infected sera tested, 15 showed significant reactivity with GM6 fusion protein (diagnostic sensitivity $79 \%$ ), 14 with the MARP1 fusion protein (diagnostic sensitivity $74 \%$ ) and 17 out of the 19 sera at least with one of the two antigens. The cumulated diagnostic sensitivity for both antigens thus was about $90 \%$. This clearly indicates that they may represent promising candidate antigens for the development of an immunodiagnostic test for trypanosome infections which is independent of trypanosome serodeme or species.

\section{DISCUSSION}

We have begun an investigation of non-variable antigens of African trypanosomes which are recognized by the bovine immune system early during infection. Heterologous screening of an expression library from $T$. $b$. gambiense with bovine serum collected early, i.e. 7 days after a $T . b$. bruce infection 
and using anti-IgM as a second antibody, resulted in the isolation of a number of phage clones, representing different genes, none of which is presumably a VSG gene. Two of these early antigens have been analysed in the present study.

Both antigens analysed, GM6 and MARP1, are high molecular weight proteins which exert structural roles in the trypanosomal cell. GM6 is localized at the flagellum/cell body interphase and is a component of the fibre network (Hemphill et al. 1991) which connects these two compartments. MARP1 is a microtubule-associated protein which is localized on the microtubules of the cell body (Schneider et al. 1988).

DNA sequencing of parts of both genes revealed that both antigens, GM6 and MARP1, consist of well-conserved, repetitive sequence motifs of different lengths (GM6, 68 amino acids; MARP1, 38 amino acids). Repetitive antigens with sequence similarity to both GM6 and MARP1 have been found in T. cruzi (Ibanez et al. 1988), representing antigens which are strongly recognized by the human host, albeit in a chronic infection. This latter observation, in conjunction with the results presented in this study on the bovine immune response and with unpublished results from this laboratory on the immune response of the mouse, indicate that GM6, MARP1 and their respective analogues are well recognized by and are strong antigens for different mammalian host species. Repetitive sequence motifs of different lengths have been found frequently in trypanosomatids by using quite different approaches and experimental concepts (Hoft et al. 1989; Wallis \& McMaster, 1987; Roditi et al. 1987; Mowatt \& Clayton, 1987; Schneider et al. 1988). The significance of this apparent abundance of highly repetitive proteins for parasite/host interaction is not clear at present (Schofield, 1991), but it should be borne in mind that repetitive structures are often $\mathrm{T}$-cell independent antigens. This may be particularly significant in the case of the African trypanosomes where the antibody-mediated, T-cell independent immune response is of major importance for controlling parasitaemia and disease (Pinder, 1984 ; Pinder, Chassin \& Fumoux, 1986).

Both, GM6 and MARP1 are equally present in bloodstream and procyclic forms of trypanosomes, and they are well conserved between different species of salivarian trypanosomes $(T . b$. brucei, $T$. congolense, $T$. evansi) and, though somewhat less, between these and the stercorarians $T$. rangeli and $T$. cruzi. Immunofluorescence staining also indicated that at least some Leishmania species do contain a similar protein. In conclusion, GM6 and MARP1 exhibit the characteristics of being (i) recognized early during infection by different mammalian hosts, and (ii) being non-variable, i.e. life-cycle-stage independent and conserved between different trypanosome species. This makes them attractive both as potential candidate antigens for vaccination studies and as antigens for the development of a diagnostic test to detect trypanosomal infections at an early stage and irrespective of trypanosome species or serodeme. In view of this latter application, the diagnostic sensitivity of GM6 and MARP1 was tested with a collection of 19 sera from different breeds of cattle infected with $T . b$. brucei or $T$. congolense. GM6 scored positive with $15 / 19$, MARP1 with $14 / 19$, while the cumulative sensitivity (GM6 plus MARP1) was 17/19. While these results are clearly preliminary, they suggest that the two antigens may be promising candidates for further development.

We are most grateful to Murray Selkirk for providing his cDNA library, to Lorenz Rindisbacher, Heike Troll, Marianne Affolter and Judith Deflorin for their help in DNA sequencing, Stefan Kunz for performing the computer analysis of the sequence data, to Tony Wyler for technical assistance in electron microscopy work and to Isabel Roditi for many stimulating discussions. We gratefully acknowledge the Swiss Tropical Institute for providing us with different trypanosomal cell extracts. This study was supported by grants obtained from the Swiss National Science Foundation (No. 31-25284.88), the Sandoz Research Foundation and the Stanley Thomas Johnson Foundation.

\section{REFERENCES}

BARNES, D. A., MOTTRAM, J., SElKIRK, M. \& AGABIAN, N. (1989). Two variant surface glycoprotein genes distinguish between different substrains of Trypanosoma brucei gambiense. Molecular and Biochemical Parasitology 34, 135-46.

BRUN, R. \& SCHÖNENBERGER, M. (1979). Cultivation and in vitro cloning of procyclic culture forms of

Trypanosoma brucei in semi-defined medium. Acta Tropica 36, 289-92.

BURGESS, D. E. \& JERRELls, T. (1985). Molecular identity and location of invariant antigens on Trypanosoma bruce i rhodesiense defined with monoclonal antibodies reactive with sera from trypanosomiasis patients. Infection and Immunity 50, 893-9.

CRoss, G. A. M. (1990). Cellular and genetic aspects of antigenic variation in trypanosomes. Annual Reviews of Immunology 8, 83-110.

DE GEE, A. L., LEVINE, R. F. \& MANSFIELD, J. M. (1988). Genetics of resistance to the African trypanosomes. VI. Heredity of resistance and variable surface glycoprotein specific immune response. Fournal of Immunology 140, 283-8.

Duvallet, G. (1984). Variants antigénetiques détectés après transmission cyclique d'un clone de Trypanosoma brucei brucei chez des bovins trypanosensibles et résistants. Revue d'Elevage et de Médicine vétérinaire des Pays tropicaux 37, 277-87. FROMMEL, T. O. \& BALBER, A. E. (1987). Trypanosoma brucei brucei, T. brucei gambiense and T. brucei rhodesiense: common glycoproteins and glycoprotein heterogeneity. Experimental Parasitology 63, 32-41. 
GOLDSTEIN, L. S. B., LAYMON, R. A. \& MCINTOSH, J. R. (1986). A microtubule associated protein in Drosophila melanogaster: identification, characterization, and isolation of coding sequences. Journal of Cell Biology 102, 2076-87.

HEMPHILL, A., LAWSON, D. \& SEEBECK, T. (1991). The cytoskeletal architecture of Trypanosoma brucei. fournal of Parasitology 77, 603-12.

HIDE, G., GRAY, A., HARRISON, C. M. \& TAIT, A. (1989). Identification of an epidermal growth factor receptor homologue in trypanosomes. Molecular and Biochemical Parasitology 36, 51-9.

HOHN, B. (1980). In vitro packaging of $\lambda$ and cosmid DNA. Methods in Enzymology 68, 299-309.

HOFT, D. F., KIM, K. S., OTSU, K., MOSER, D. R., YOST, W. J., BLUMIN, H., DONELSON, J. E. \& KIRCHHOFF, L. v. (1989). Trypanosoma cruzi expresses diverse repetitive protein antigens. Infection and Immunity 57, 1959-67.

HYUNH, T. V., YOUNG, R. A. \& DAVIS, R. W. (1985). Construction and screening cDNA libraries $\lambda \mathrm{gt} 10$ and $\lambda$ gt11. In DNA Cloning 1 (ed. Glover, D. M.), pp. 49-78. Oxford: JRL Press.

IBANEZ, C. F., AFFRANCHINIO, J. L., MACINA, R. A., REYES, M. B., Leguizamon, S., CAMARgo, M. E., ASLUND, L., PETTERSSON, U. \& FRASCH, A. C. C. (1988). Multiple Trypanosoma cruzi antigens containing tandemly repetitive amino acid sequence motifs. Molecular and Biochemical Parasitology 30, 27-34.

LAEMMLI, U. K. (1970). Cleavage of structural proteins during the assembly of the head of the bacteriophage T4. Nature, London 227, 680-5.

LAWSON, D. (1983). Epinemin: a new protein associated with vimentin filaments in non-neuronal cells. Fournal of Cell Biology 97, 1891-905.

mowatt, M. R. \& Clayton, C. E. (1987). Developmental regulation of a novel repetitive protein of Trypanosoma brucei. Molecular and Cellular Biology 7, $2838-44$

NORRANDER, T., KEMPE, T. \& MESSING, J. (1983).

Construction of improved M13 vectors using oligodeoxynucleotide-directed mutagenesis. Gene 26, 101-6.

PARSONS, M. N. \& NIELSEN, B. (1990). Active transport of 2-deoxy-D-glucose in Trypanosoma brucei procyclic forms. Molecular and Biochemical Parasitology 42, 197-204

PINDER, M. (1984). Trypanosoma congolense: Genetic control of resistance to infection in mice. Experimental Parasitology 57, 185-91.

PINDER, M., CHASSIN, P. \& FUMOUX, F. (1986).
Mechanisms of self-cure from Trypanosoma congolense infection in mice. Journal of Immunology 136, 1427-34.

RODITI, I., CARRINGTON, M. \& TURNER, M. (1987). Expression of a polypeptide containing a dipeptide repeat is confined to the insect stage of Trypanosoma brucei. Nature, London 325, 272-4.

SAMBROOK, J., FRITSCH, E. F. \& MANIATIS, T. (1989). Molecular Cloning. 2nd Edn. Cold Spring Harbor: Cold Spring Harbor Laboratory Press.

SANGER, F., NICKLEN, S. \& COULSON, A. R. (1977). DNA sequencing with chain terminating inhibitors.

Proceedings of the National Academy of Sciences, USA 74, 5463-7.

SCHOFIELD, L. (1991). On the function of repetitive domains in protein antigens of Plasmodium and other eukariotic parasites. Parasitology Today 7, 99-105.

SCHNEIDER, A., HEMPHILL, A., WYLER, T. \& SEEBECK, T. (1988). Large microtubule-associated protein of T. bruce $i$ has tandemly repeated, near-identical sequences. Science 241, 459-62.

SEED, J. R. \& SECHELSKI, J. (1987). The role of antibody in African trypanosomiasis. Fournal of Parasitology 73, 840-2.

SHAPIRO, s. z. \& MURRAY, M. (1982). African trypanosome antigens recognized during the course of infection in N'Dama and Zebu cattle. Infection and Immunity 35, 410-16.

SOUTO-PADRON, T., REYES, M. B., LEGUIZAMON, S., CAMPETElla, o. E., FRASCH, A. c. C. \& DE zoUza, w. (1989). Trypanosoma cruzi proteins which are antigenic during human infections are located in defined regions of the parasite. European fournal of Cell Biology 50, 272-8.

TOWBIN, H., STAEHELIN, T. \& GORDON, J. (1979).

Electrophoretic transfer of proteins from polyacrylamide gels to nitrocellulose sheets: procedure and some applications. Proceedings of the National Academy of Sciences, USA 76, 4350-4.

VOGEL, M., GOTTSTEIN, B., MÜLLER, N. \& SEEBECK, T. (1988). Production of a recombinant antigen of Echinococcus multilocularis with high immunodiagnostic sensitivity and specificity. Molecular and Biochemical Parasitology 31, 117-26.

WALLIS, A. E. \& MCMASTER, W. R. (1987). Identification of Leishmania genes encoding proteins containing tandemly repeating proteins. Fournal of Experimental Medicine 166, 1814-24.

WEBSTER, P. \& SHAPIRO, s. z. (1990). Trypanosoma bruceia membrane-associated protein in coated endocytotic vesicles. Experimental Parasitology 70, 154-63. 